\title{
A Comparative Study of The Cure Characteristics, Mechanical Properties and Abrasion Resistance of Silica and Carbon Black Filled NBR/SBR Blends
}

\author{
Ebtesam E. Ateia ${ }^{1}$, D. E. El-Nashar*2, H. H. Hassan ${ }^{1}$ and A. K. Abd El-Aziz ${ }^{1}$ \\ ${ }^{1}$ Physics Department, Faculty of Science, Cairo University, Giza and ${ }^{2}$ Department of \\ Polymers and Pigments, National Research Centre, Dokki, Cairo, Egypt.
}

\begin{abstract}
COMPARISON between incompatible and compatible blend of nitrile rubber (NBR) and styrene butadiene rubber (SBR) with acrylonitrile butadiene styrene (ABS) is studied. Physical rheological characteristics and abrasion resistance for the investigated samples are performed. The use of acrylonitrile butadiene styrene (ABS) as compatibilizer improves the abrasion resistance of the blends. The results indicated that filled blends with carbon and silica offer processing advantages over unfilled blends. The ultrasonic and scanning electron microscope (SEM) are used to analyze the obtained data.
\end{abstract}

Keywords: Rubber, Rheology, Microscopy, Blend, polymer, Abrasion resistance.

\section{Introduction}

In general, physical properties of vulcanized rubber blend compounds are influenced by morphology and distribution of compounding ingredients between the phases of the blend. The properties of filler have the most effective on rubber vulcanizes are the surface area, particle size, and the structure. In fact, silica and carbon black are the only fillers with a fine enough particle size to be classified as fully reinforcing [1]. One of the obstacles for formulating new blends is to foretell how additives will affect the phase behavior and enhance the properties of the material, especially when these polymers are not miscible and their blending leads materials to have weak interfacial adhesion and poor mechanical performances. One of the classical methods to ensure adhesion between the phases (reduction the interfacial tension) is using a third component, named compatibilizer, which is usually a macromolecule designed to treat the interfacial properties. Recent years, blends of acrylonitrile butadiene rubber (NBR) and styrene butadiene rubber (SBR) have been widely used in industry [2]. Many of incompatible blends are appearing in multiphase morphology. These blends become compatible by adding a suitable compatibilizing agent in low concentrations. One of the most successful compatibilizers is acrylonitrile butadiene styrene (ABS) [3]. Generally, these interfacial modifications have generated a great advantage in materials based on polymers as polymer blend or poly blends. These agents are enhancing the interaction between the material components, such interaction carries out for the inter phase [4]. The objective of the work is to compare between pure blend NBR/SBR and blend loaded with optimum nano-filler of carbon black and white silica in order to reach more applicable blends. The main target is to improve the abrasion resistance of the compatible blends.

\section{Experimental}

Two rubber groups were prepared with different ratios of NBR/SBR blends [B1, B2, B3] and [S0, S1, S2, S3] with and without compatilizer of Acrylonitrile-Butadiene-Styrene Terpolymer (ABS), which were defined in Table 1. All samples were prepared by melt mixing of the components in a Brabender Plasticorder . Generally, ABS was inserted into the Brabender, preheated to $160^{\circ} \mathrm{C}$ for $8 \mathrm{~min}$, and then NBR and SBR were added. The mixer was operated at $160-170^{\circ} \mathrm{C}$, maintaining the rotor speed at $70 \mathrm{rpm}$ for $10 \mathrm{~min}$ according to [ASTM D15-72; 2007] [5]. The optimum white and black filled blends [BB30, BW50] were also prepared under the same conditions. The optimum cure time of each compounded rubber mix was detected using a Monsanto Rheometer. Samples for testing were compression molded in a laboratory hydraulic press (Mackey Bowley, $\mathrm{C} 1136 / 99$, Gravesend, Kent, England) at $152 \pm 1^{\circ} \mathrm{C}$ according to their suitable times for vulcanization.

*Corresponding author e-mail:doaaelnashar@yahoo.com

DOI : 10.21608 /ejchem.2017.828.1033

C2017 National Information and Documentation Center (NIDOC) 


\section{Ultrasonic measurements}

The longitudinal ultrasonic velocities were measured in the different blend Samples using the pulse-echo technique. The elapsed time between the initiation and the receipt of the pulse appearing on the screen of flaw detector (USIP20, Krautkramer, Germany) was measured by standard electronic circuit (54615 B, Hewlett Packard) oscilloscope. Theoretically, the velocity of longitudinal wave $v$ in solid was related to material's density $\rho$, Young's modulus E and Poisson's ratio $\sigma$ by the following equation [6]

$$
v=\sqrt{\frac{E(1-\sigma)}{\rho(1+\sigma)(1-\sigma)}}
$$

The ultrasonic wave velocity can be given by the following equation $[7,8]$

$$
V=2 d / \Delta t \quad \mathrm{~m} / \mathrm{s}
$$

where $\mathrm{d}$ was the sample thickness and $\Delta \mathrm{t}$ was the time interval. The accuracy of velocity measurements was estimated to be $( \pm 0.04 \%)$. The longitudinal modulus L was calculated [8] from ultrasonic longitudinal velocity and the density of the isotropic materials as shown in Equation (3)

$$
L=\rho v^{2} \quad(P a)
$$

The attenuation coefficient $(\alpha)$ was then calculated from the following equation $[6,9]$ $\alpha=\left(\frac{20}{2 d}\right) \log \frac{A_{1}}{A_{2}} \quad \mathrm{~dB} / \mathrm{cm}$

where $A_{1}$ and $A_{2}$ were the heights (amplitudes) of two successive echoes displayed on the cathode ray oscilloscope. The estimated accuracy of the ultrasonic attenuation is about $( \pm 0.08 \%)$.

\section{Abrasion resistance measurements}

Determination of the abrasion resistance for rubber was performed according to [ASTM D53516; 87(2010)] [10] using Zwick abrasion tester model 6102.

The abrasion loss was calculated according to the following equation:

$$
A=\frac{\Delta m \cdot s}{\rho \cdot s}
$$

where A was the abrasion loss in $\mathrm{mm}^{3} \Delta \mathrm{m}$ was the loss in mass $(\mathrm{mg}), \rho$ was the density $\left(\mathrm{g} / \mathrm{cm}^{3}\right)$, $\mathrm{S}$ was the nominal abrasive grade $(200 \mathrm{mg})$ and $\mathrm{S}$ was the abrasive grade in $\mathrm{mg}$.

Density measurements

Density $\left(\mathrm{g} / \mathrm{cm}^{3}\right)$ was calculated by hydrostatic method according to [ASTM D297-93][11] as follows

$$
P=\frac{0.9971 \times A}{A-(B-C)}
$$

where A (gm), was the mass of specimen, B (gm),

\begin{tabular}{|c|c|c|c|c|c|c|c|c|c|c|}
\hline Ingredients (phr) $^{\mathbf{a}}$ & So & S1 & $\mathbf{S 2}$ & S3 & S4 & B1 & B2 & B3 & BW50 & BB30 \\
\hline SBR & 100 & 75 & 50 & 25 & 0 & 75 & 50 & 25 & 50 & 50 \\
\hline NBR & 0 & 25 & 50 & 75 & 100 & 25 & 50 & 75 & 50 & 50 \\
\hline Stearic acid & 2 & 2 & 2 & 2 & 2 & 2 & 2 & 2 & 2 & 2 \\
\hline Sulpher & 1.5 & 1.5 & 1.5 & 1.5 & 1.5 & 1.5 & 1.5 & 1.5 & 1.5 & 1.5 \\
\hline Processing oil & 10 & 10 & 10 & 10 & 10 & 10 & 10 & 10 & 10 & 10 \\
\hline $\mathrm{ZnO}$ & 5 & 5 & 5 & 5 & 5 & 5 & 5 & 5 & 5 & 5 \\
\hline TMTD $^{b}$ & 1.7 & 1.7 & 1.7 & 1.7 & 1.7 & 1.7 & 1.7 & 1.7 & 1.7 & 1.7 \\
\hline $\operatorname{IPPD}(4020)^{\mathrm{C}}$ & 1 & 1 & 1 & 1 & 1 & 1 & 1 & 1 & 1 & 1 \\
\hline $\begin{array}{l}\text { Comp a tabilizer } \\
(\mathrm{ABS})^{\mathrm{b}}\end{array}$ & - & 一 & - & 一 & - & 5 & 5 & 5 & 5 & 5 \\
\hline Stearic acid & 2 & 2 & 2 & 2 & 2 & 2 & 2 & 2 & 2 & 2 \\
\hline Silica (Hi-Sil) & - & 一 & 一 & 一 & 一 & 一 & 一 & 一 & 50 & 一 \\
\hline $\operatorname{SAF}(\mathrm{N} 115)^{\mathrm{c}}$ & - & - & - & - & - & - & - & - & - & 30 \\
\hline
\end{tabular}
was the mass of specimen and supporting wire in water and $\mathrm{C}(\mathrm{gm})$, was the mass of supporting wire in water.

TABLE 1. Composition of pure compatible, incompatible and loaded NBR/SBR blends.

a: Part per hundred parts of rubber. b: Acrylonitrile-Butadiene-Styrene terpolymer. c: Super Abrasion Furnace Black.

b: Tetramethyl thiuram disulfide.

c : N-isopropyl-N-phenyl-p-phenylene diamine.

Egypt.J.Chem. 60 , No.5 (2017) 


\section{Scanning electron microscopy (SEM)}

The surface morphology of the samples was examined through scanning electron microscope (SEM; (Philips, FEI inspect F, Holland) at the accelerating voltage of $200 \mathrm{~V}-30 \mathrm{kV}$, with magnification up to $150000 \mathrm{X}$ and resolution $1.2 \mathrm{~nm}$ at $30 \mathrm{kV}(\mathrm{SE}) / 3.0 \mathrm{~nm}$ at $1 \mathrm{kV}(\mathrm{SE})$.). The middle part of the cross section of the specimens was chosen as representative of the overall morphology.

\section{$\underline{\text { Results and Discussion }}$}

\section{Ultrasonic and density investigations}

Figure (1:a-d) shows the variation of the blend density $\rho$, the ultrasonic wave velocity $\mathrm{V}$, the ultrasonic longitudinal elastic modulus $\mathrm{L}$ and the attenuation coefficient $\alpha$ with NBR content, for the incompatible and compatible NBR/ SBR blends. It is clear that the incompatible blend NBR/SBR deviates from linearity with an addition of NBR content. This deviation is mainly due to immiscibility of the two parent rubber components of NBR/SBR blends. However the addition of 5phr ABS increases the linearity of the blend density, ultrasonic wave velocities, and ultrasonic longitudinal elastic modulus. Earlier it was reported $[12,13]$, that a relation between a composition of the blend and density is linear, which indicates the compatibility of the blend, also the complete miscibility of two rubber components in each other [14]. Such behavior demonstrates the basis of aggregation and variation of the polymer which leads to the formation of one homogeneous phase [15]. On the other hand, the nonlinearity behavior is shown in Fig.(1) which indicates that the mixing of two parent rubber is very poor due to the bad inter-rubber inter-chains between blend components. Such behavior appears the presence of more than one phase which indicates the incompatibility behavior of the blend system. The appearance of more than one maximum peaks indicates that the two parent rubber components are incompatible and the two phases have separate relaxation process. This blend system represents the incompatible blend [12-17] as shown in Fig. (1: d). Generally, adding the compatibilizer to the blend has many advantages such as, provides the adhesion between the constituent phases, permits achieving a finer dispersion and stabilizes the morphology [18].
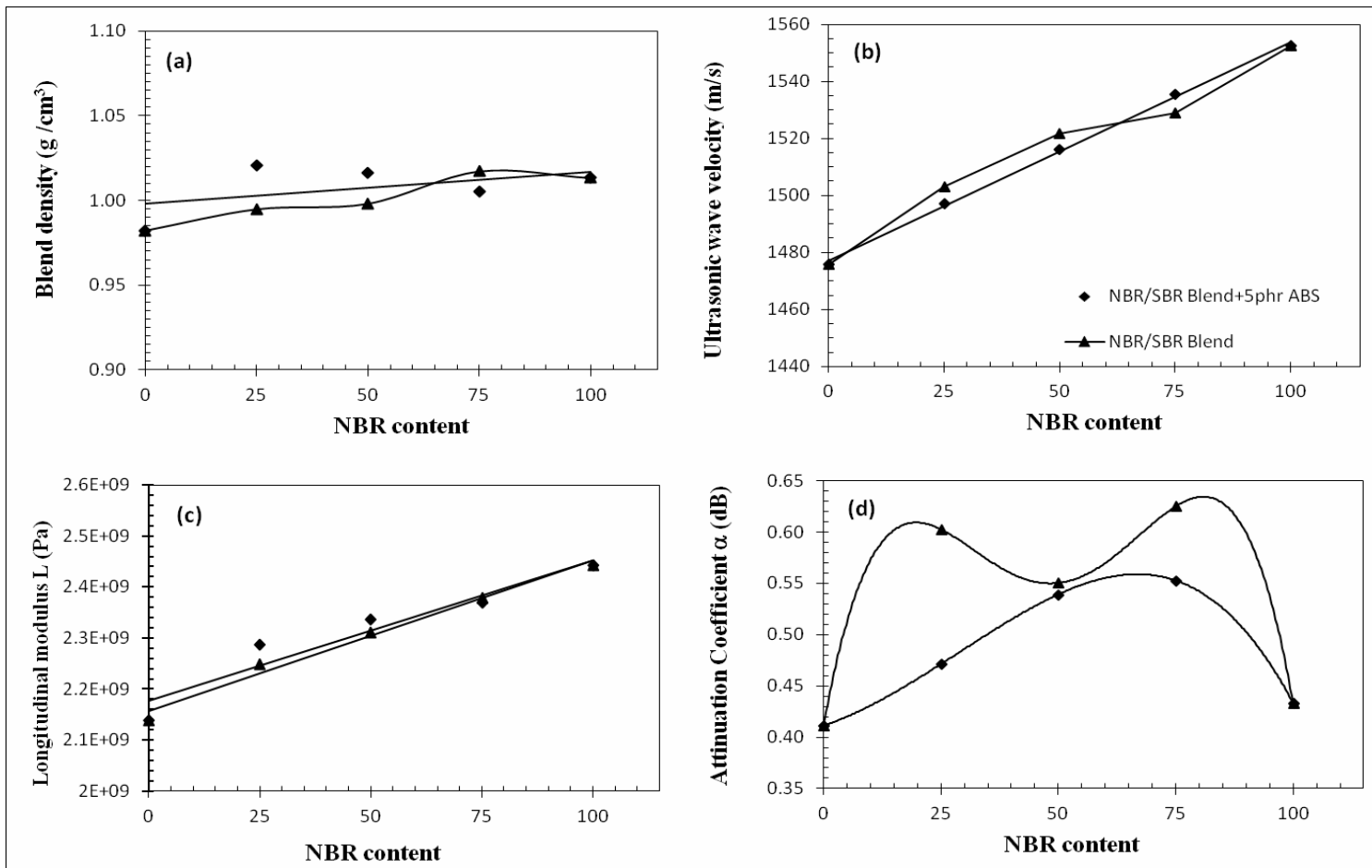

Fig. (1:a-d). The variation of (a) the blend density, (b) the ultrasonic wave velocity, (c) the ultrasonic longitudinal elastic modulus and (d) the attenuation coefficient $\alpha$ with NBR content, for the incompatible and compatible NBR/SBR blends . 


\section{Phase Morphology and surface Analysis}

Figure (2:a-h) shows scanning electron microscopy of the investigated samples. The pure samples NBR (S4) and SBR (S0) are shown in Fig.(2:a-b), one can see a clear shape for a single phase of homogenous distribution of the rubber ingredients with no voids. It is clear from Figure (2:c, e, g) that the blend mixtures of NBR have lower dispersion into the SBR matrix as in $\mathrm{S} 1\left(\frac{25 N B R}{75 S B R}\right)$ sample. Further increase of the NBR as in S2 $\left(\frac{50 N B R}{50 S B R}\right)$ sample increases the immiscibility and phase separation, as clear from Figure (2: e). Fig. (2: g) shows S3 $\left(\frac{75 N B R}{25 S B R}\right)$ sample which possesses the immiscibility and phase separation but with different ratios. These results agree well with the previous discussion of the ultrasonic incompatibility.

The investigated samples with compatibilizers (B1 $\left.\left(\frac{25 N B R}{75 S B R}\right)+5 \mathrm{phr} A B S\right), \mathrm{AB} 2\left(\left(\frac{50 N B R}{50 S B R}\right)+5 \mathrm{phr}\right.$ $\mathrm{ABS})$ and $\mathrm{B} 3\left(\left(\frac{75 N B R}{25 S B R}\right)+5 \mathrm{phr} \mathrm{ABS}\right)$ are almost likely to have miscible blends as shown in (2: d, $\mathrm{f}, \mathrm{h}$ ). Finally, the homogeneity of the mixture can be controlled by using either proper mixing conditions or by addition of compatibilizers as in present work. The higher miscibility of the blends $\mathrm{B} 1$ and $\mathrm{B} 3$ can be attributed to high disperse phase fraction as shown in Figure (3: A) rather than the co-continuous blend morphology as in Figure (3: B). Furthermore, they may have phase inversion structure; this will be confirmed by the rheological properties. So the addition of ABS compatibilizer brought the stability to the system by reaching semi-dispersed phases while the blends without compatibilizer tend to form separate phase morphologies and have low thermal stabilities.

\section{Rheological Studies}

The rheological characteristics of the NBR/SBR blends without and with $5 \mathrm{phr}$ compatibilizer of ABS are shown in Tables (2) and (3) respectively, where $M_{L}$ is the minimum torque which reflects minimum viscosity for the mixes and it is taken as a measure of the extent of mastication. It is noticed that the minimum torque $M_{L}$ nearly decreases for both NBR/SBR blends with and without compatibilizer, but with different ratios. This can be attributed to the increase in the viscosity with less slippage at the interface. Generally, ABS compatibilizer decreases the interfacial tension and increases the interaction between NBR and

Egypt.J.Chem. 60 , No.5 (2017)
SBR blend, leading to a compatible blend [19]. $\mathrm{M}_{\mathrm{H}}$ is the maximum torque indicated the crosslink density for rubber vulcanized. It is clear from tables ( 2 and 3 ) both incompatible and compatible blends, $\mathrm{M}_{\mathrm{H}}$ decreases with increasing NBR content up to 50:50 NBR/SBR (S2 and B2) and then increases. This is due to the phase inversion phenomenon of the domains for NBR/SBR compositions [20]. From the table, it is clear that the $\mathrm{M}_{\mathrm{H}}$ has maximum values for the investigated samples loaded with white and black nanofillers. This can be attributed to two factors the first is the presence of filler in the rubber matrix, which decreases the mobility of the macromolecular [21]. While the other is due to the formation of some hydrogen bonding reducing strong binding of rubber blend to filler surfaces [22]. $t_{s 2}$ is the scorch time which measures the premature time of the mixes vulcanizates begins. $t_{C 90}$ is the optimum curing time for vulcanization. The regardless behavior of the single phases ( $\mathrm{S} 0$ and $\mathrm{S} 4)$, the addition of ABS increases the cure time $t_{C 90}$ as well as increasing the apparent crosslink density. These results can be related to the increase of the melt viscosity and confirm the strong interaction at the interface between the rubber phases. The effect of the compatibilizer on the curing time is clearly seen in the blend loaded with carbon black BB30. The cure rate index (CRI) measures vulcanization rate based on the difference between $t_{C 90}$ and $t_{S 2}$.

It can be calculated from the relation [23]

$$
\mathrm{CRI}=100 /\left(t_{C 90}-t_{S 2}\right)
$$

The dilution of the incompatible blends with NBR content decreases the CRI, due to the partial diffusion and partial miscibility of the blend. While for the compatible blends, the CRI increases with increasing NBR, due to the accelerating effect as well as the high softening point of ABS block copolymer $\left(\approx 230^{\circ} \mathrm{C}\right)$. The $\mathrm{CRI}$ for the samples filled with carbon black is reduced due to the function of carbon to accelerate the vulcanization process. While the addition of silica increases CRI due to silica-accelerator system interaction. Other researchers $[24,25]$ observed a similar trend in the filled rubber. The apparent crosslink density $\Delta t$ can be calculated from the following equation [26]

$$
\Delta \mathrm{t}=\mathrm{M}_{\mathrm{H}}-\mathrm{M}_{\mathrm{L}}
$$

The overall view of " $\Delta t$ " values enhances our expectation of the phase inversion for both incompatible and compatible NBR/SBR blends around $\mathrm{S} 2$ and $\mathrm{B} 2$. 

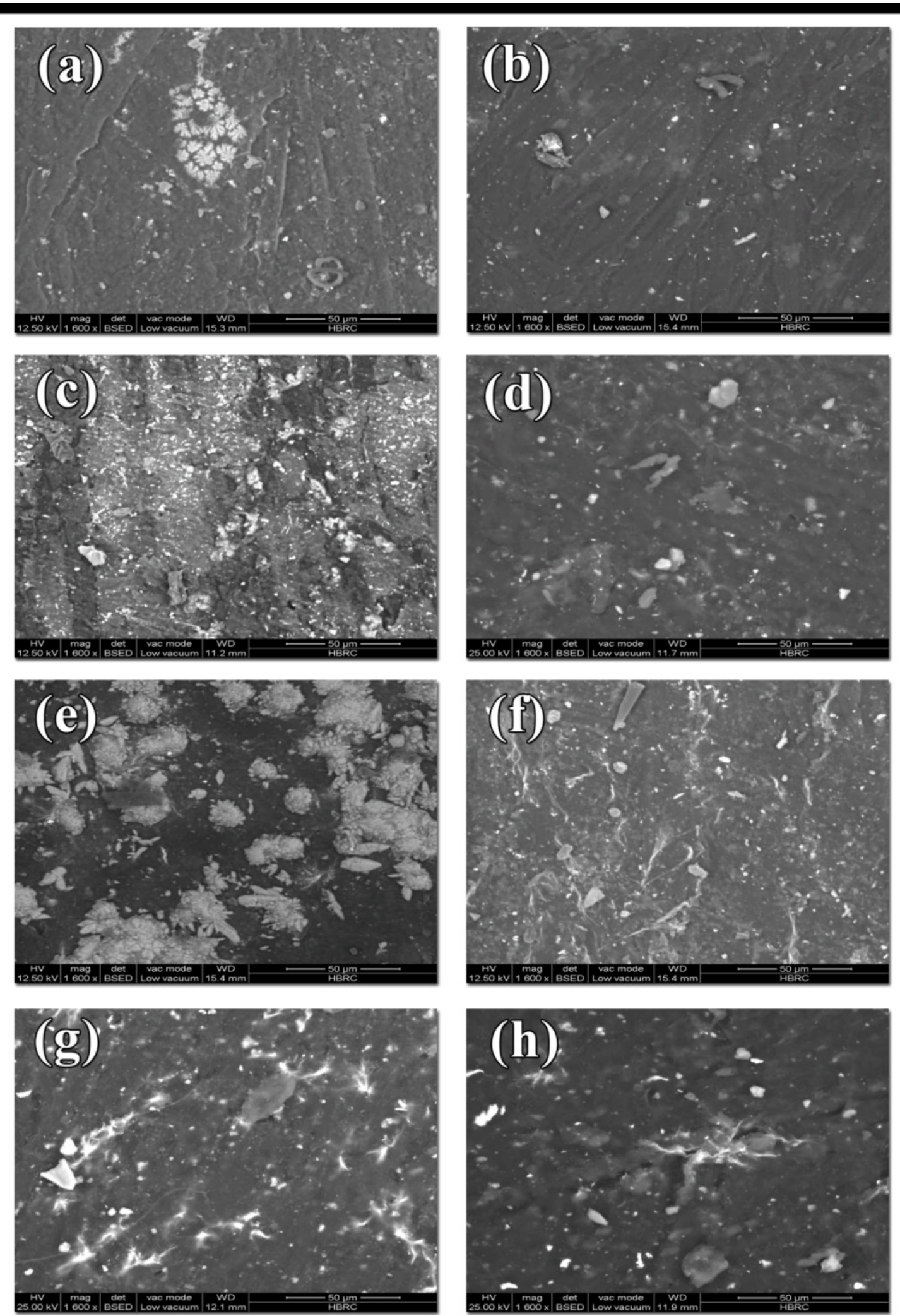

Fig. 2.The scanning electron microscopy (SEM) of (a) S0 (SBR), (b) S4 (NBR), (c) S1((25 NBR)/(75 SBR)) (d) B1(S1+5phr ABS), (e) S2 ((50 NBR)/(50 SBR)), (f) B2(S2+5phr ABS), (g) S3 ((75 NBR)/(25 SBR)), (h) B3 $(\mathrm{S3}+5 \mathrm{phr} \mathrm{ABS})$ respectively. 

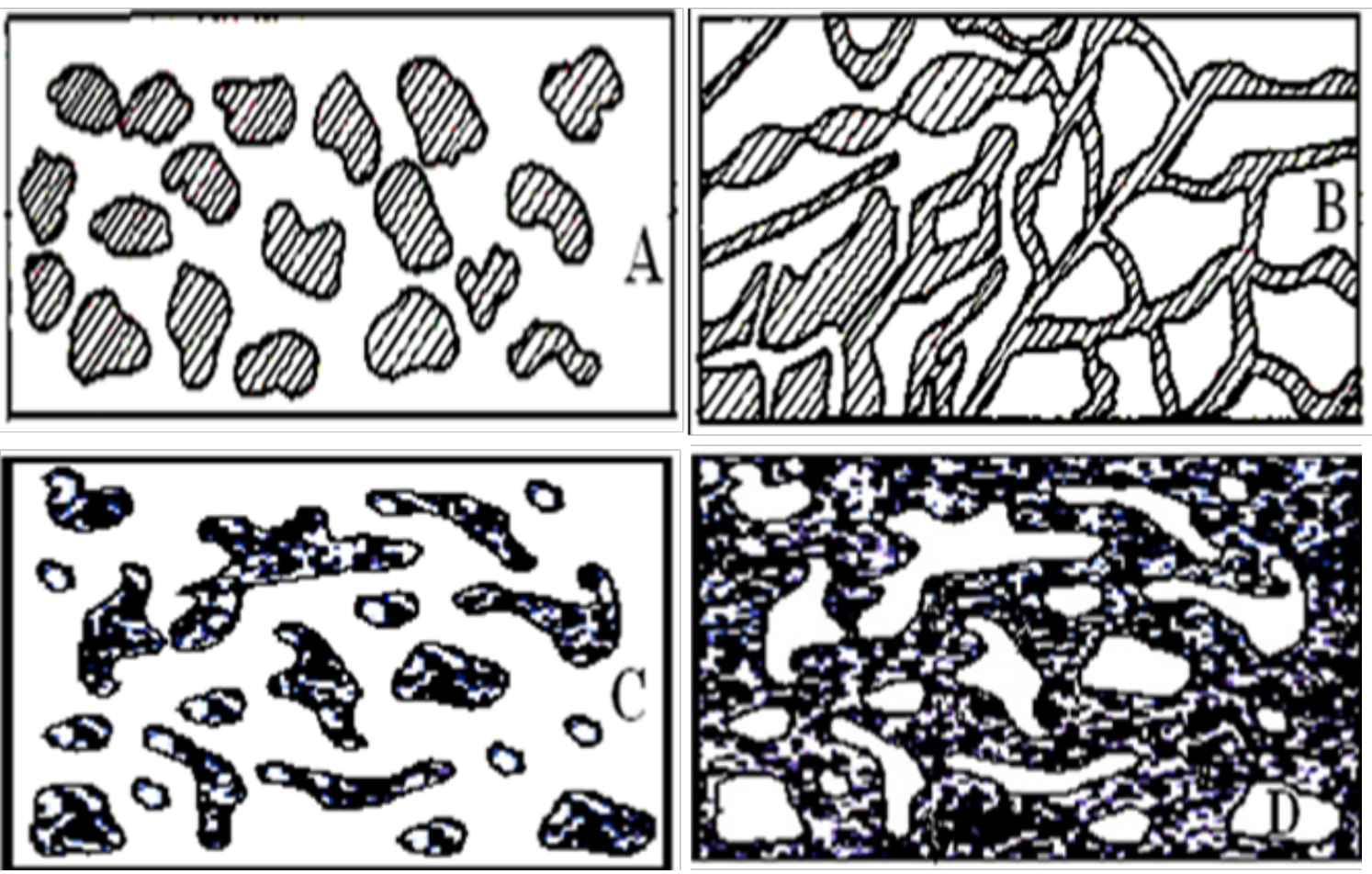

Fig. (3:a-d). Represents the (A) Dispersion, (B) co-continuous, and (C,D) phase inversion type morphologies.

TABLE 2. Rheological characteristics of the incompatible NBR/SBR blends .

\begin{tabular}{|c|c|c|c|c|c|c|c|}
\hline Sample & $\begin{array}{c}\text { NBR } \\
\text { Content }\end{array}$ & $\begin{array}{c}M_{L} \\
\text { (1b.in) }\end{array}$ & $\begin{array}{c}M_{H} \\
\text { (1b.in) }\end{array}$ & $t_{c 90}(\min )$ & $t_{\mathrm{s} 2}(\min )$ & $\begin{array}{c}\text { CRI } \\
\left(\mathrm{min}^{-1}\right)\end{array}$ & $\begin{array}{c}D t=\left(M_{H}-M_{L}\right) \\
(\text { (1b.in) }\end{array}$ \\
\hline S0 & 0 & 0.52 & 6.49 & 3.44 & 2.18 & 79.37 & 5.97 \\
\hline $\mathrm{S} 1$ & 25 & 0.46 & 4.95 & 2.40 & 1.62 & 128.21 & 4.49 \\
\hline $\mathrm{S} 2$ & 50 & 0.41 & 4.89 & 2.64 & 1.7 & 106.38 & 4.48 \\
\hline S3 & 75 & 0.35 & 5.61 & 2.98 & 1.67 & 76.34 & 5.26 \\
\hline S4 & 100 & 0.3 & 6.95 & 3.56 & 1.8 & 56.82 & 6.65 \\
\hline
\end{tabular}

TABLE 3. Rheological characteristics of the compatible NBR/SBR blends with 5phr ABS .

\begin{tabular}{|l|c|c|c|c|c|c|c|c|}
\hline Sample & $\begin{array}{c}\text { NBR } \\
\text { Content }\end{array}$ & $\begin{array}{c}\mathbf{M}_{\mathbf{L}} \\
(\mathbf{1 b . i n})\end{array}$ & $\begin{array}{c}\mathbf{M}_{\mathbf{H}} \\
(\mathbf{1 b . i n})\end{array}$ & $\mathbf{t}_{\mathbf{c 9 0}}(\mathbf{m i n})$ & $\mathbf{t}_{\mathbf{S} \mathbf{2}}(\mathbf{m i n})$ & $\begin{array}{c}\mathbf{C R I} \\
(\mathbf{m i n}-\mathbf{1})\end{array}$ & $\begin{array}{c}\Delta \mathbf{t}\left(\mathbf{M}_{\mathbf{H}}-\mathbf{M}_{\mathbf{L}}\right) \\
(\mathbf{1 b . i n})\end{array}$ & $\alpha \mathbf{f}$ \\
\hline S0 & 0 & 0.52 & 6.49 & 3.44 & 2.18 & 79.37 & 5.97 & -- \\
\hline B1 & 25 & 0.35 & 6.21 & 3.67 & 1.87 & 55.56 & 5.86 & -- \\
\hline B2 & 50 & 0.36 & 4.57 & 3.50 & 1.97 & 65.36 & 4.21 & -- \\
\hline B3 & 75 & 0.37 & 5.99 & 3.19 & 1.73 & 68.49 & 5.62 & -- \\
\hline S4 & 100 & 0.30 & 6.95 & 3.56 & 1.8 & 56.82 & 6.65 & -- \\
\hline BW50 & 50 & 1.35 & 9.50 & 3.19 & 1.81 & 72.46 & 8.15 & 1.08 \\
BB30 & 50 & 3.98 & 16.25 & 8.47 & 2.27 & 16.13 & 12.27 & 2.56 \\
\hline
\end{tabular}

Egypt.J.Chem. 60 , No.5 (2017) 
The variations in torque with different concentration of fillers can be used to characterize the filler matrix interaction. Reinforcement factor $\alpha_{f}$ estimated from the rheographs [27] and is given by:

$$
\alpha_{f}=\frac{\left[\Delta L_{\max }(\text { filled })-\Delta L_{\max }(\text { gum })\right]}{\Delta L_{\max }(\text { gum })}
$$

where $\Delta \mathrm{L}_{\max }$ (filled) and $\Delta \mathrm{L}_{\max }$ (gum) are the variations in $\mathrm{M}_{\mathrm{H}}$ during processes of vulcanization for the filled and gum blends respectively. The calculated $\alpha_{\mathrm{f}}$ for both BB30 and BW50 are listed in Tables (3). It is clear from the Table that, $\alpha_{\mathrm{f}}$ for black filler BB30 is greater than of white filler BW50 this can be attributed to strong interfacial between rubber and filler.

\section{Abrasion resistance}

Figure (4:a-b) represents the variation of the abrasion loss for the compatible and the incompatible NBR/SBR blends with both the time and the NBR content respectively. As shown from the figure the abrasion loss increases linearly with time for all the investigated samples. While it decreases with the increasing NBR content for the blends without compatibilizer. From the figure, it is clear that SBR phase has higher abrasion loss than NBR containing the same amount of carbon black, which is in line with our expectation.
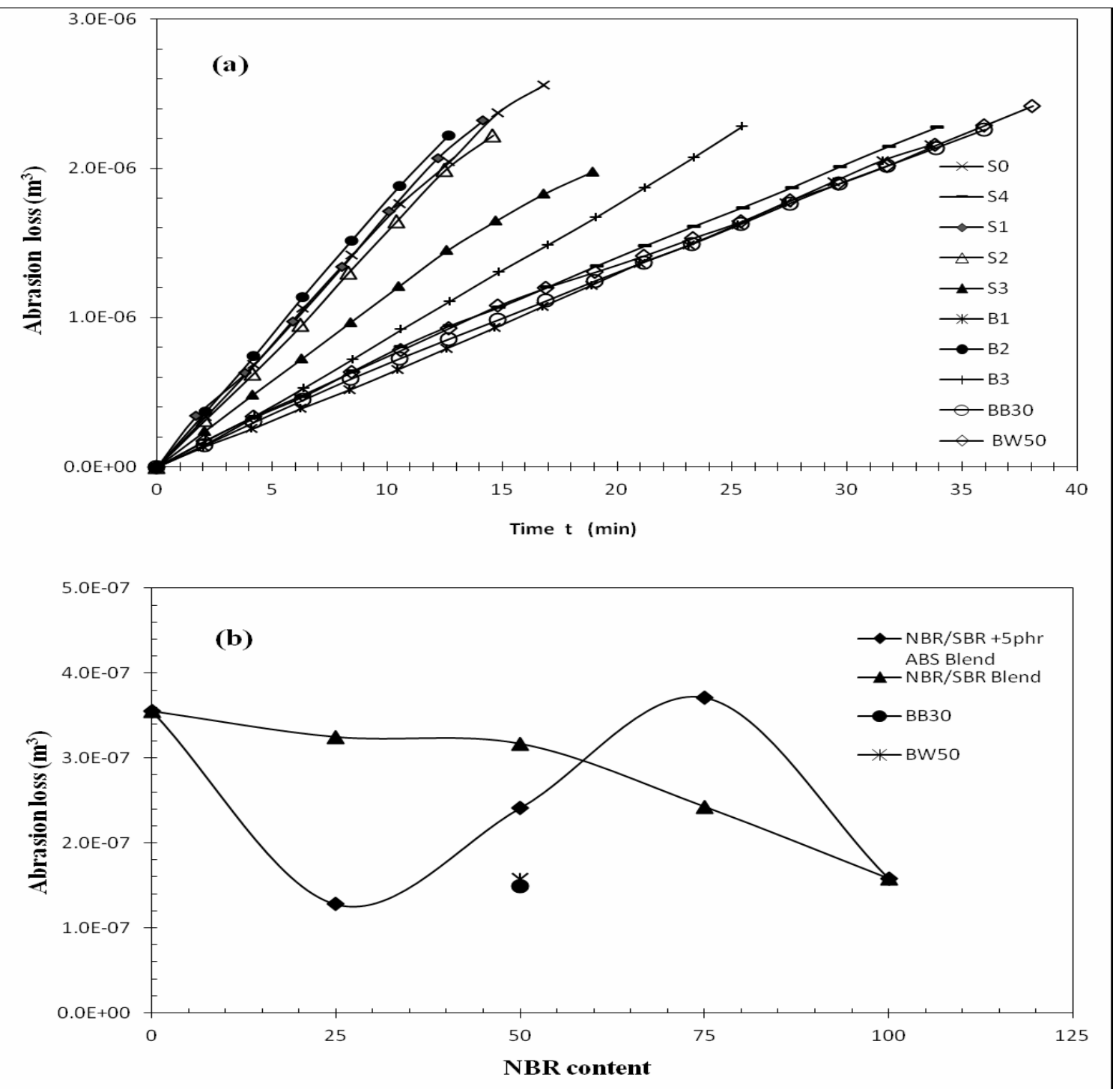

Fig. (4:a-b). Relation between the abrasion loss of different NBR/SBR blends (a) with time $\mathrm{t}(\mathrm{min})$ and (b) with the NBR content. 
The polarity nature of the blend acquired from NBR C $\equiv \mathrm{N}$ and the type of covalent crosslinks formed in the blends are the main causes of the obtained behavior. On the other hand, the abrasion loss has a fluctuating behavior with NBR content for the compatible blend. This fluctuation is attributed to the appearance of both majority and minority phases according to the interaction between the compatibilizer and the blend content. For the loaded blends with SAF (BB30) and silica (BW50) fillers, the reinforcing fillers with rubber matrix leading to the lessening of abrasion loss. This is attributed to good dispersion of nanofiller in the rubber matrix, which forms an efficient layer which enhances the degree of curing[28]. The small amount of the investigated nanoparticulate filler was lead to good dispersion in rubber chain matrix and consequently, the properties of rubber vulcanizates were enhanced [24].

\section{Conclusion}

1- The addition of $5 \mathrm{phr}$ of ABS terpolymer enhances the compatibility of NBR/SBR blends.

2- The ultrasonic wave velocity, attenuation coefficient, and longitudinal modulus reveal that the blends (S1, S2, S3) are incompatible blends, however, the blends with $\mathrm{ABS}(\mathrm{B} 1, \mathrm{~B} 2)$ are compatible, except the sample B3.

3- The nano- filled blends with SAF black BB30 $\left(\left(\frac{50 N B R}{50 S B R}\right)+5 \mathrm{phr} \mathrm{ABS}+30 \mathrm{phr} \mathrm{SAF}\right)$ and white silica BW50 $\left.\left(\frac{50 N B R}{50 S B R}\right)+5 \mathrm{phr} \mathrm{ABS}+30 \mathrm{phr}\right)$ have high abrasion resistance, also, they are miscible and completely compatible .

\section{Acknowledgements}

The authors would like to express their sincere appreciation and thanks to prof. Dr. Nadia Abd El- All and their team work at Laboratory of Ultrasonic, National Institute of Standards (NIS), Giza, Egypt, for her guiding, supporting and measurements.

\section{References}

1. Wanvimon, A. and Garry, L. , A comparative study of the cure characteristics, processability, mechanical properties, ageing, and morphology of rice husk ash, silica and carbon black filled $75: 25$ NR/EPDM blends, J. of Appl. Polym. Sci. 109, 932 (2008).

Egypt.J.Chem. 60 , No.5 (2017)
2. Ismail H., Yusof, A., Blend of waste poly(vinylchloride) $\quad(\mathrm{PVCw}) /$ acrylonitrile butadiene-rubber (NBR): The effect of maleic anhydride (MAH). Polym. Test. 23 (6), 675 (2004).

3. Mahendrasinh Raj M., Studies on mechanical properties of PC - ABS blends, Int. Appli. Sci. And Eng. Res. 3(2),279 (2014).

4. de Sousa, F. D.B. ,Mantovani G. L., Scuracchio C. H. , Mechanical properties and morphology of NBR with different clays, Polymer Testing, 30,819 (2011).

5. Methods of Compound and Sample Preparation for Physical Testing of Rubber Products ASTM D 2007, 15

6. Bobing H., Yang Y. , Hou Z. , Qin Z., Qiang F. ,Fast determination of phase inversion in polymer blends using ultrasonic techniqu, Polym. 46,7624 (2005).

7. Higazy A. A. , Afifi H. , Khafagy A.H., El-Shahawy M.A., Mansour A.M., Ultrasonic studies on polystyrene/styrene butadiene rubber polymer blends filled with glass fiber and talc, Ultrasonics 44, el 439 (2006).

8. Mechanical properties measurements ASTM D 41206; 2006 .

9. Darwish N.A. , Abd El-Aal N. , Abd El-Megeed A.A. , Effect of addition of hdpe and ldpe on rheological, mechanical, elastic and compatibility behavior of sbr/nbr rubber blend system. Polym. Plast. Technol. Eng. 46,345 (2007).

10. Abrasion resistance measurements ASTM D53516; (1987).

11. Standard test methods for rubber products - chemical analysis: hydrostatic method for determination of the Density D297-93 (reapproved 1998)1-7.

12. Sidkey M.A. , Abd El-Fattah A.M. , Yehia A.A. , Abd El-All, N.S. Ultrasonic investigation of some rubber blends, J.Appl. Polym. Sci. 43,1441 (1991).

13. Ward A.A., El-Sabbagh S., Abd El-Aal N.S., Mechanical, ultrasonic, dielectric and physical properties of natural rubber: different concentrations of zinc stearate, KGK. Kautschuk, Gummi, Kunststoffe 61 (9), 429 (2008).

14. Guru G.S., Prasad P. , Shivakumar H. and Rai SK. , Miscibility, thermal and mechanical studies of methylcellulose/poly (vinyl alcohol) blends. Int . 
Res. In Pharmacy Chem, 2(4), 957 (2012).

15. Sidkey M.A., Yehia A.A., Abd El-Malak A.A. , Gaafar M.S. , "Compatibility studies on some rubber blend systems by ultrasonic techniques Mater", Materials Chemistry And Physics. 74,23 (2002).

16. Sidkey M.A., Abd El-Fattah A.M., Abd El-Aal N.S.N.S., Compatibility studies on some solutions of rubber blends by ultrasonic techniques, J. Appl. Polym. Sci. 46,581 (1992).

17. Thomas G.V., Gopinathan Nair M.R., Ultrasonic investigation on compatibility of PVC-modified liquid natural rubber blends, J. Appl. Polym. Sci. 69(4),785 (1998).

18. Van Puyvelde P.V. , and Moldenaers P. , Rheology and morphology development in immiscible polymer blends, Rheol. Rev. 101,145 (2005).

19. Arayapranee W. and Rempel G.L. , Properties of NR/EPDM blends with or without Methyl Methacrylate-Butadiene-Styrene (MBS) as a compatibilizer , Int. J. of Mater. \& Structural Reliability 5(1), 1 (2007).

20. Willemse R.C., De Boer Posthuma A., Van Dam J. , Gotsis A.D. , Co-continuous morphologies in polymer blends, Polym. 39 (24), 5879 (1998).

21. Bokobza L. ., Mechanical and electrical properties of elastomer nanocomposites based on different carbon nanomaterials, Journal of Carbon Research, 3(10), 1, (2017).

22. Xu T. , Jia Z., Wu L., Chen Y., Luo Y., Jia D. , Peng $Z$. ., Influence of acetone extract from natural rubber on the structure and interface interaction in NR/ silica composites, Applied Surface Science, 423,43
(2017).

23. Darwish N.A., Shehata A.B., Abd El-Megeed A.A. , Halim S.F. , and Mounir A. , Compatibilization of SBR/NBR blends using poly acrylonitrile as compatibilizer, Polym. Plast. Technol. Eng. 44,1297 (2005)

24. Sae-oui P. , Rakdee C. , Thanmathorn P. , Use of rice husk ash as filler in natural rubber vulcanizates: In comparison with other commercial fillers, $J$ Appl. Polym Sci 83, 2485 (2002).

25. Ahmed K. , Nizami S. S., Riza N. Z., Reinforcement of natural rubber hybrid composites based on marble sludge/Silica and marble sludge/rice husk derived silica, Journal of Advanced Research,5 (2), 165, (2014).

26. Ahmed K. , Nizami S. S., Raza N. Z., Shirin K. Cure characteristics, mechanical and swelling properties of marble sludge filled EPDM modified chloroprene rubber blends, Advances in Materials Physics and Chemistry, 2, 90, (2012).

27. Ateia E., El-Nashar D. E., Hassan H. H., Abd El-Aziz, A. K. A comparative study of the pure and nano-filled acrylonitrile butadiene -styrene butadiene rubber blends, American Journal of Materials Science and Application, 3(3), 44 (2015) .

28. Mishra S. and Shimpi G., Comparison of nano $\mathrm{CaCO} 3$ and flyash filled with styrene butadiene rubber on mechanical and thermal properties, $J$, Sci. Ind. Res. 64,744 (2005).

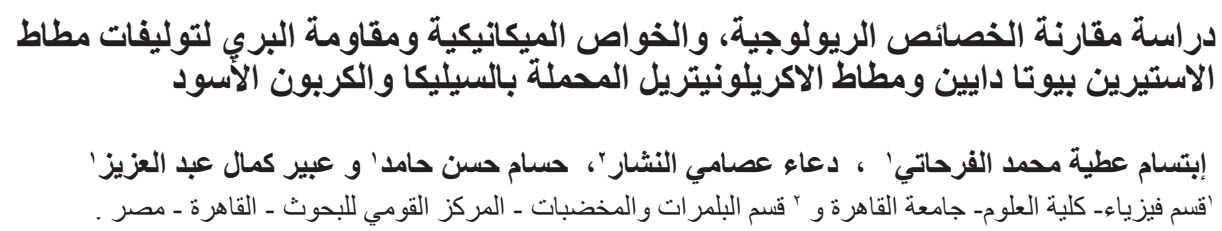

